\title{
Investigation on Flexural Behaviour of Cold Formed Steel Latticed Built-Up I Section with Drop Web
}

\author{
N. Nandhini ${ }^{1}$ and K. Sudha ${ }^{2}$ \\ ${ }^{1}$ PG Student, ${ }^{2}$ Assistant Professor, \\ Department of Civil Engineering, Government College of Engineering, Salem, Tamil Nadu, India \\ E-Mail: nandhininagarajan32@gmail.com, sudhajaikishan@gmail.com
}

\begin{abstract}
This paper deals with the study of flexural behaviour of cold formed latticed built-up I beam with drop web for various sections by varying depth, thickness and span length of the section. The numerical analysis was carried out by FEM software ABAQUS 6.13[11]. The experimental works carried out by Cheng Yu and Benjamin W. Schafer (2006) [1] were taken for validating the numerical analysis procedure. It provides a cost effective way to explore the performance of products in a virtual environment. The ultimate capacity is obtained by performing both linear and non-linear analysis. Theoretical investigation as per AISI specification was carried out for all the specimens to check the accuracy of the design proposal. Numerical finite element procedure is used to instruct the effect of various parameters on behavior of beams. The critical load and different modes of failure are studied by this numerical investigation. Comparison between deformed shape and load vs. displacement curves of I section with drop web were presented.
\end{abstract}

Keywords: Abaqus, Built up Beam, Cold formed section, Drop Web, Latticed

\section{INTRODUCTION}

Cold-formed steel beams are commonly used in civil construction as both primary (floor joists, structural members) and secondary (girts and purlins). These sections are extensively used in various engineering applications because of their high strength to weight ratio. Thin walled I sections are preferred mostly due to their light weight and full strength characteristics. Cold formed steel members are typically thin walled, i.e. local plate buckling and cross section distortion should be consider as an essential part of member design.

Cheng Yu and Benjamin W. Schafer (2006) [1] have investigated the distortional buckling of cold formed steel C and $\mathrm{Z}$ sections. In this investigation they have selected the test details to allow distortional buckling to form, but restrict lateral-torsional buckling to the extent possible. Yu and Schafer [3] presented another method to generate distortional buckling in cold formed steel $\mathrm{C}$ and $\mathrm{Z}$ beam and they also found that large strength reduction occurs as the distortional buckling is initiated instead of local buckling. In case of latticed steel members, a bar with circular crosssection is very stiff torsionally and flexurally.

Though many studies have been performed on buckling of cold formed steel profiles, few studies have been made on latticed / built-up cold-formed beams. The research woks performed on CF built up sections under bending are fewer than the works on compression members.

Christopher D. Moen, Benjamin W. Schafer (2010) [12] has studied on Extended Direct Strength Design to cold formed steel beams with holes. The existing expressions for beams without holes have been modified to limit flexural capacity to the strength of net cross section.

Maguncki and P.Paczos (2009) [4] has investigated coldformed thin-walled channel beams with open and closed profile of drop flanges. This paper aims to provide a methodology that would enable the development of optimised CFS beam sections with maximum flexural strength for practical applications.

\section{FINITE ELEMENT MODELLING}

The FE software ABAQUS 6.13 (2013) [11] was used to simulate the numerical model of cold-formed steel built up I beams. The finite element method is a numerical analysis technique for obtaining approximate solutions to wide variety of engineering problems. Most of the engineering problems today make it necessary to obtain approximate numerical solutions to problems rather than exact closed form solutions. ABAQUS 6.13 [11] is a general purpose finite element modelling package for numerically solving a wide variety of mechanical problems.

For numerical analysis the I section has been chosen, which consists of an approximate idealised mid-line model with four-noded doubly curved shell with reduced integration (S4R) - for plates and angle stiffener and a 10 node quadratic tetrahedron (C3D10) element for lacing are chosen. The developed modeling includes geometric nonlinearity.

Built up I-section has been created by using 4 angles connected back to back. The stiffeners were provided at the ends and 1/3rd of the span. Lacing bar of $10 \mathrm{~mm}$ was used to introduce a gap between the angles so that the radius of gyration can be improved. The front view of the angles with drop and 3D view of the built up section is shown in figure 1 and figure 2 respectively.

Mesh size was given as $5.0 \mathrm{~mm}$. The connection was given 


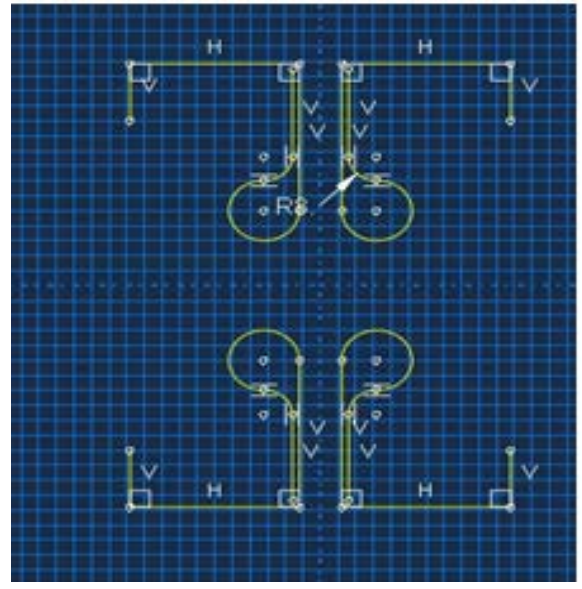

Fig. 1 Front view of the angles with drop

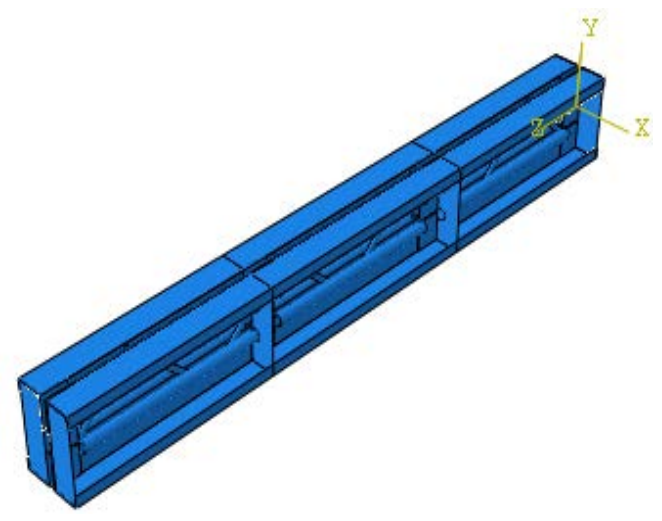

Fig. 2 3D view of the built up section

between stiffener and angle and angle and lacing to act as combined unit by using tie command in ABAQUS [11]. The closed drop web was formed by using tie between the outer and inner flange at regular interval. Boundary conditions were given by specifying the nodal point index and then restraining the necessary displacement components. For simply supported end condition, displacements components $\mathrm{U} 1, \mathrm{U} 2$ and $\mathrm{U} 3$ are restrained at one end and $\mathrm{U} 1$ and $\mathrm{U} 2$ are restrained at another end. Linear buckling analysis was done to obtain buckling load and buckling modes. In non-linear analysis displacement control analysis with static riks step was used.

\section{A. Validation}

The experimental tests done by Cheng Yu and Benjamin W. Schafer (2006) [1] as reference, a numerical model was validated. The measured dimensions and geometrical details for the validated section were shown in figure 3 and Table 1 .
1. Depth of section, $\mathrm{h}$ $=205 \mathrm{~mm}$
2. Width of section, $\mathrm{b}$ (compression) $\quad=51 \mathrm{~mm}$
3. Width of section, $\mathrm{b}$ (Tension) $\quad=51 \mathrm{~mm}$
4. Thickness, $\mathrm{t}$

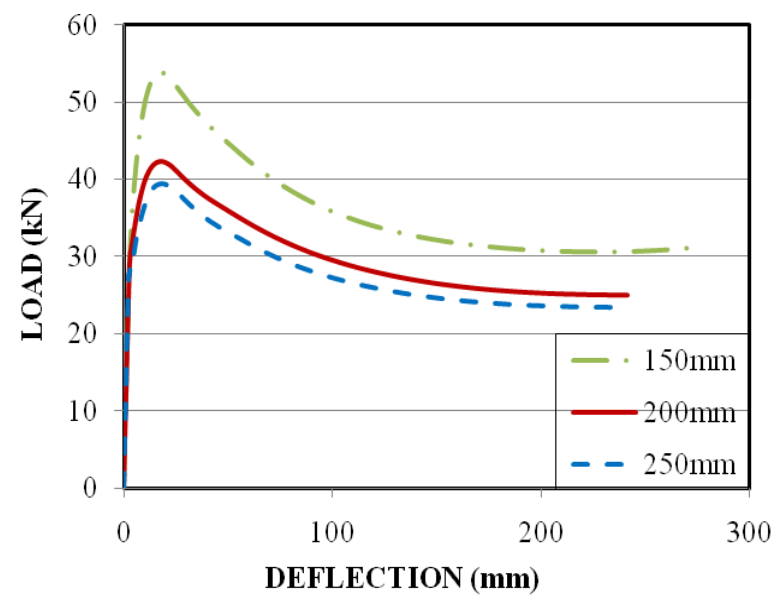

Fig. 3 Cross section of the validated section
1. Depth of compression lip,dc
$=17 \mathrm{~mm}$
2. Depth of Tension lip,dt
$=17 \mathrm{~mm}$
3. $\theta \mathrm{c}$
$=86.7^{\circ}$
4. $\theta \mathrm{t}$
5. $\mathrm{r}($ Compression $)$
$=83^{\circ}$
6. $\mathrm{r}$ (Tension)
$=7 \mathrm{~mm}$
$=8 \mathrm{~mm}$

TABLE I MATERIAL PROPERTIES OF C SECTION

\begin{tabular}{|c|c|c|}
\hline Specimen ID & $\mathbf{E}\left(\mathbf{N} / \mathbf{m m}^{2}\right)$ & Yield Stress(N/mm $\mathbf{~})$ \\
\hline D8C097-5E4W & 20300 & 576.9 \\
\hline
\end{tabular}

The comparison between the ultimate moment of the tested specimen and those computed by the finite element analysis were presented in Table 2 .

\section{TABLE II COMPARISON OF EXPERIMENTAL AND FEA ULTIMATE MOMENT CAPACITY}

\begin{tabular}{|c|c|c|c|}
\hline $\begin{array}{c}\text { Specimen } \\
\text { Dimension }\end{array}$ & $\begin{array}{c}\text { Experimental } \\
\text { Ultimate } \\
\text { Moment(kNm), } \\
\mathbf{M}_{\text {Exp }}\end{array}$ & $\begin{array}{c}\text { Finite Element } \\
\text { method } \\
\text { Ultimate } \\
\text { moment (kNm), } \\
\mathbf{M}_{\text {FEA }}\end{array}$ & $\mathbf{M}_{\text {Exp }} / \mathbf{M}_{\text {FEA }}$ \\
\hline $\begin{array}{c}\text { D8C097- } \\
\text { 5E4W }\end{array}$ & 18.7 & 17.602 & 1.06 \\
\hline
\end{tabular}

\section{PARAMETRIC STUDY}

After validated the FE model, the procedure was adopted for numerical analysis to obtain results over a wide range of section geometries. The aim of this parametric study is to investigate the flexural behavior and the factors governing the behavior of the section.

A total of $12 \mathrm{FE}$ models of Cold formed steel built up beam with drop web with an angle size 50 X 50 (all in mm), beam lengths of $1200 \mathrm{~mm}, 1500 \mathrm{~mm}, 1800 \mathrm{~mm}$ and $2000 \mathrm{~mm}$, two different thickness of $2.5 \mathrm{~mm}$ and $3.2 \mathrm{~mm}$ and three depths of $150 \mathrm{~mm}, 200 \mathrm{~mm}, 250 \mathrm{~mm}$, with b/t ratio varying from 15.625 to 20 were analyzed in the FE package ABAQUS [11]. The yield stress values for varying thickness was obtained by 
coupon tests prescribed by IS 1663-1960 part 1. Specimen Labeling is described below.

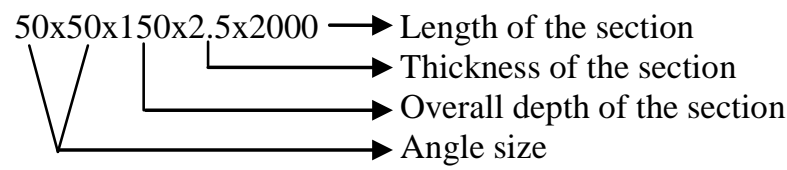

The deformation shape for the section 50x50x150x2.5x1200 obtained from non-linear analysis is shown in figure 4.

The following figures 5,6,7,8 show the relationship between the ultimate load and deflection for the different cross sections studied.

\section{A. Effective Width Method (EWM) AS PER AISI S100:2007}

As per AISI S100:2007 the effective width of the section was calculated and thereby effective section modulus and effective area of the sections were obtained. Nominal

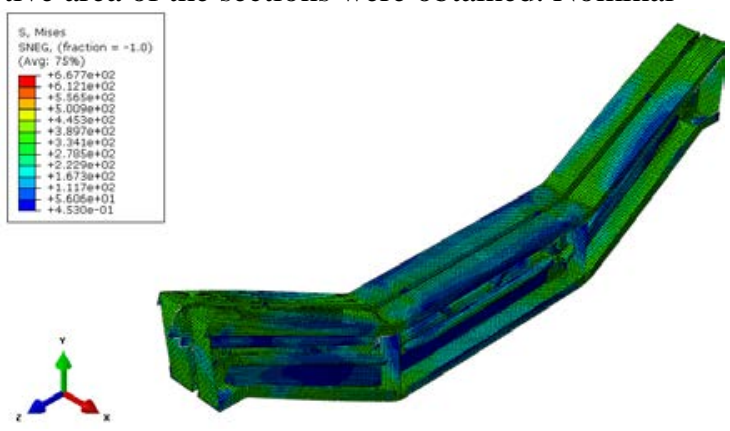

Fig. 4 Deformed shape of the section 50x50x150x2.5x1200

Flexural strength $\left(M_{n}\right)$ was calculated by using effective section modulus. Using gross section properties initial yield moment $\left(\mathrm{M}_{\mathrm{y}}\right)$ was obtained, further lateral torsional buckling resistance $\left(\mathrm{M}_{\mathrm{ne}}\right)$, local buckling resistance $\left(\mathrm{M}_{\mathrm{nl}}\right)$ and the

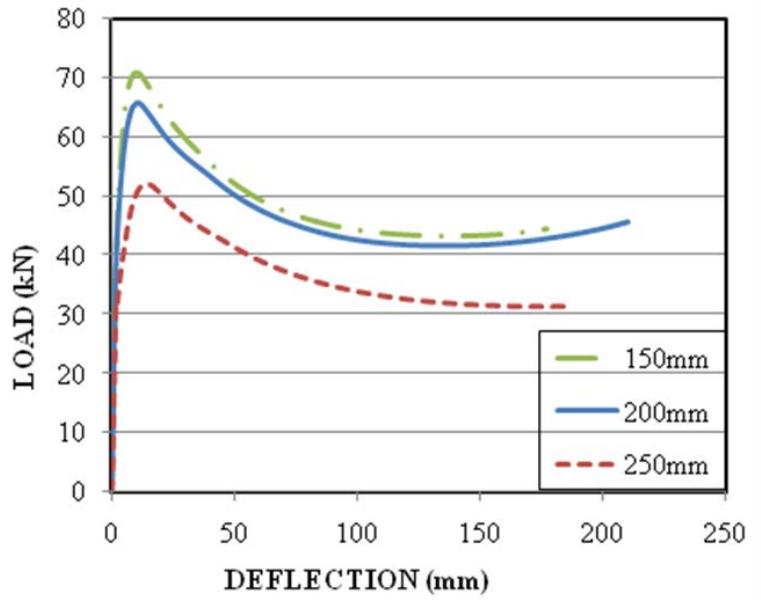

Fig. 5 Load vs Deflection (50x50x2.5-1200)

distortional buckling resistance $\left(\mathrm{M}_{\mathrm{nd}}\right)$ were calculated for 12 built up I beams. CUFSM software was used to obtain geometric properties for the effective sections since it is tedious procedure to calculate the section properties for built up sections manually.
The mean value of FEA-to-predicted moment ratio $\left(\mathrm{M}_{\mathrm{FEA}} / \mathrm{M}_{\mathrm{EWM}}\right)$ is 0.93 . The comparison of FEA results AISI (EWM) with strengths are plotted in Figure 9. It is shown that the current AISI (EWM) predictions are conservative for the cold-formed steel built up I sections with lower depth.

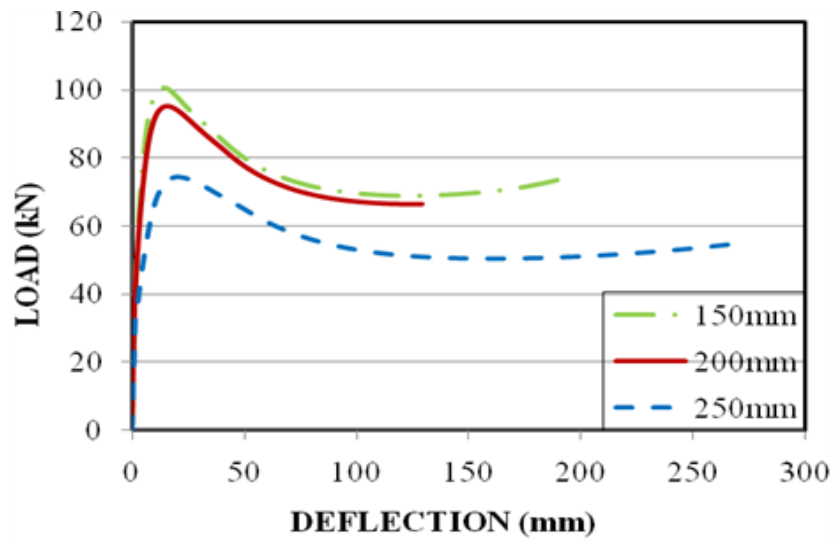

Fig. 6 Load vs. Deflection 50x50x3.2x1200

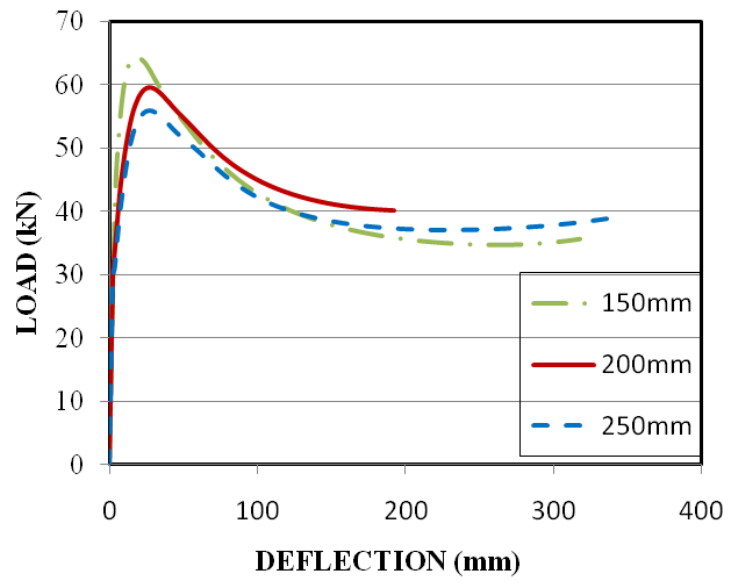

Fig. 7 Load vs. Deflection (50x50x3.2x2000)
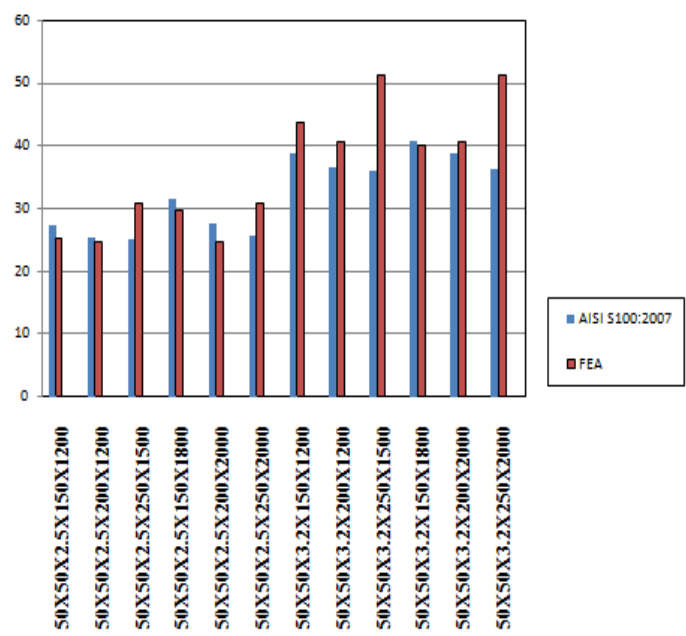

Fig. 8 Comparison of predicted strength between AISI (EWM) and FEA 


\section{CONCLUSIONS}

Numerical and theoretical investigation on the flexural behaviour of cold formed steel built up i beam with drop web flexural members has been presented in this paper. The fe model of flexural members were developed and verified by comparison of experimental results reported by cheng yu and BenjaminWw. Schafer (2006) [1] in terms of moment capacities using fe software abaqus. Having validated the fe model, further numerical analyses were conducted with wide range of section geometries. Then the numerical results were compared with the design strength predicted by effective width method as per AISI s100:2007. Finally, based on the comparison of results, the following conclusions are drawn.

1. The impact of changing geometric properties of the cold-formed built up i beams, ultimate moment carrying capacity calculated by abaqus (mfea) decreases with increase in depth of the section due to inadequate stiffener.

2. Introducing a drop in web increases the moment carrying capacity of the section.

3. For sections having higher depth, the empirical equations given by codal provisions are required to modify to study the flexural behavior of the built up sections.

4. Based on the comparison of results between finite element analysis and AISI (EWM), codal results are conservative for the sections studied with lower depth.

\section{REFERENCES}

[1]Cheng Yu and Benjamin W. Schafer, "Distortional Buckling of Cold Formed Steel Beams”, Journal Of Structural Engineering (ASCE), Vol. 132, No. 45, pp. 15-28, 2006.

[2]Jun Ye, Iman Hajirasouliha, Jurgen Becque and Kypros Pilakoutas, "The Development of more Efficient Cold-Formed Steel Channel Sections in Bending”, 2015.

[3]Cheng Yu and Benjamin W. Schafer, "Simulation of Cold Formed Steel in Local and Distortional Buckling”, Journal of Constructional Steel Research, Vol. 3, No. 1, pp. 581-590, 2006.

[4]K. Magnucki and P. Paczos, "Theoretical shape optimization of coldformed thin-walled channel beams with drop flanges in pure bending", Journal of Constructional Steel Research, Vol. 65, pp. 1731-1737, 2009.

[5]K. Maguncki, P. Paczos and J. Kasprazak, "Elastic buckling of coldformed thin-walled channel beams with drop flanges", Journal of Structural Engineering, ASCE, Vol. 136, pp. 886-896, 2010.

[6]M. Macdonald, M. A. Heiyantuduwa Don, M. Koteko ban and Rhodes, "Web Crippling Behaviour Of Cold-Formed Thin-Walled Steel Lipped Channel Beams” Journal of Structural Eng ASCE, Vol. 127, No. 10, pp. 1137-44, 2010.

[7]K. Sudha and S. Sukumar, "Behaviour of Cold-Formed Steel Built-up I Section Under Bending”, International Journal of Engineering and Technology, Vol. 5, No. 6, pp. 0975-4024, Dec 2013-Jan 2014.

[8] M. Vijayasimhan, V. Marimuthu, G. S. Palani and P. Rama Mohan Rao, "Comparative Study on Distortional Buckling Strength of Coldformed Steel Lipped Channel Section", Research Journal of Engineering Sciences, ISSN 2278-9472, 2013.

[9]M. Karunakaran and M. Helen Shanti, "FE Analysis of Hollow Flanged Cold-Formed Steel Z Beams", International Journal of Civil Engineering and Applications, 2013.

[10] T. Srinath and M. Shanmugarajan, "Effect of Web opening on the Bending Behaviour of Cold Formed Steel Built-Up 'I' Section”, International Journal of Science, Environment And Technology, Vol. 5, No. 1, pp. 102-110, 2016.
[11] ABAQUS, Dassault Systems Simulia Corp, ABAQUS Standard User's Manual Version 6.13 USA, 2013.

[12] Christopher D. Moen and Benjamin W. Schafer, "Extending Direct Strength Design Design to Cold Formed Steel Beam with Holes”, 20th International Specialty Conference on Cold Formed Steel Structures, St. Louis, Missouri, USA, 2010. 